\title{
Silicon Valley in the South
}

\author{
Vale do Silício no Sul
}

MITSUHIRO KAGAMI* AKIFUMI KUCHIKI* $*$

RESUMO: Novas tendências estão ocorrendo nas indústrias manufatureiras lideradas por empresas multinacionais (EM). A globalização e a liberalização, juntamente com a revolução da tecnologia da informação (TI), aceleraram o setor de "fábulas" na economia de rede, ou seja, terceirizar processos de produção e aquisição global de peças por multinacionais. Como consequência disso, a função principal da multinacional mudou de fabricante para prestadora de serviços, terceirizando processos de produção para fabricantes de contratos estrangeiros (EMs). Na verdade, o NAFTA transformou o México em uma plataforma de produção para os EUA e o Canadá, além de países da América Latina. Podemos observar essas mudanças dramáticas, por exemplo, em Guadalajara, no México, agora chamado de "Vale do Silício no Sul". Como as multinacionais usam seus nomes de marca para vender produtos, suas funções comerciais se aproximam da indústria da moda. Eles comercializam seus produtos da mesma maneira que a Gucci e a Chanel vendem produtos de design original com os nomes de suas marcas. Portanto, o design e o marketing do produto se tornam muito importantes para as multinacionais alcançarem sucesso nos negócios, enquanto os fornecedores domésticos foram deixados para trás para o fornecimento de peças e componentes nesta nova cadeia de suprimentos global.

PALAVRAS-CHAVE: Clustering industrial; política industrial; globalização.

ABSTRACT: New trends are now taking place within manufacturing industries led by multinational corporations (MNCs). Globalization and liberalization together with the information technology (IT) revolution has accelerated "fables" industry in the network economy, i.e. outsourcing production processes and global parts procurement by MNCs. As a consequence of this, the primary function of the MNC has changed from that of manufacturer to 'service' provider by outsourcing production processes to foreign contract manufacturers (CMs). NAFTA in fact mutated Mexico into a production platform toward the US and Canada as well as Latin American countries. We can observe these dramatic changes, for instance, in Guadalajara in Mexico, now called the "Silicon Valley in the South". Since MNCs

* Institute of Developing Economies Japan External Trade Organization - IDE-JETRO, Tokyo, Japan. E-mail: mitsuhiro_kagami@ide.go.jp

** Institute of Developing Economies Japan External Trade Organization - IDE-JETRO, Tokyo, Japan. E-mail: akifumi_kuchiki@ide.go.jp. 
use their brand names to sell products, their business function becomes close to that of the fashion industry. They market their products in the same way as Gucci and Chanel sell products of original design carrying their brand names. Therefore, product design and marketing become highly important for MNCs to achieve success in business while domestic providers have been left behind for their parts and components supply in this new global supply chain. KEYWORDS: Industrial clustering; industrial policy; globalization.

JEL Classification: L60; L11.

\section{INTRODUCTION}

Thailand, Indonesia and South Korea faced economic crises successively in 1997, which also resulted in minus economic growth in some countries. These economic crises were caused by currency and financial disorders brought about by huge deficits in the current account balances of payments in those nations. A major cause of the deficits in the trade balance was sluggish export business in the electric and electronic industry in 1996 and 1997. The decline in exports was attributed to the passing of an equipment replacement cycle, interruption in the introduction of new products and new models in the market, and a sudden fall in DRAM prices due to excessive facility investment and product surplus in South Korea and other countries. In 1999, Taiwan's leading personal computer (PC) maker, Acer, announced withdrawal from the North American home-use PC market. Motorola purchased the Japanese semiconductor company established jointly with Toshiba and turned it into Motorola's Asian headquarters. Texas Instruments broke up the joint venture formed with Hitachi, and increased investment to expand its own business operations in Japan. These moves clearly indicated the poor business performance of Asian electronic companies.

Meanwhile, electronic and information industries outside Asia, particularly those in the United States, recorded favorable business results, and their business recorded strong growth. One may wonder why the American industries enjoyed prosperity while those in Asia declined.

In the electronic and information industries, dramatic reforms are being carried out today amid economic liberalization. Globalization is creating an era of megacompetition that affects companies around the world. Even major companies face serious business problems unless they continue their cost cutting and efficiency improving efforts. These changing conditions are affecting the foundations of the management systems of manufacturing companies in all stages ranging from sales, production and purchase (parts procurement) to product design and R\&D. This new trend calls for effective supply chain management. Giant companies such as IBM are conducting dramatic and speedy restructuring of management systems to provide maximum customer satisfaction, with a special focus on outsourcing. IBM's policies and speed of action are astonishing. Companies that cannot keep up with this trend will be forced out of business. 
During our visit to the industrial cluster located in Guadalajara, Mexico, we observed current changes which have not yet affected Japanese industries.

\section{INDUSTRIAL CLUSTER IN GUADALAJARA}

Guadalajara is located $570 \mathrm{~km}$ northwest of Mexico City, and it is the state capital of Jalisco. Guadalajara has been inviting companies from around the world to establish business operations in the city since the $60 \mathrm{~s}$, and the area has grown and it is commonly called the "Silicon Valley of Mexico" or "Silicon Valley in the South."

Guadalajara is suited to the establishment of such companies because of the following reasons:

(A) Many universities are located in the area, allowing easy recruitment of engineers and technicians.

(B) Good transportation and communications infrastructures have been established.

(C)The state and city governments promote policies that aim to support and foster such industries.

(D)The climate is mild and offers a comfortable living environment.

There are six universities in and around the city of Guadalajara, such as the Universidad de Guadalajara, Universidad Autónoma de Guadalajara, Instituto Tecnológico y de Estudios Superiores de Monterrey (Guadalajara Campus), Universidad Panamericana and ITESO. There are also many technical and vocational schools in the area. These institutions make Guadalajara's educational standard as high as that of Mexico City and Monterrey. Compared with areas near the US border, it is easier to secure high-quality engineers and technicians in Guadalajara. Second to Mexico City in population, Guadalajara has some 5 million residents, and people in Guadalajara are relatively young (average age: 19 years old) so factory workers are abundant.

Guadalajara can be accessed easily by air (flights to and from Los Angeles, Dallas/Fort Worth, Houston etc.). Since many electronic parts and products are lightweight, they can be transported quickly and conveniently by air. Surface roads are also extensive. There is a highway that connects Guadalajara to Monterrey and Nuevo Laredo (982 km in length), then crosses the boarder and leads to Houston. Guadalajara is only about $280 \mathrm{~km}$ from the port of Manzanillo on the Pacific coast. This port is evaluated as the second best port facility in Mexico next to Veracruz. It handled 7,220,000 tons of cargo and 276,500 (TEU) containers in 1998.

The state government actively invites and encourages overseas companies to establish facilities in Guadalajara. To make the city attractive to companies, the government has provided industrial parks and improved infrastructure in the area along the El Salto highway near the airport (for example, El Salto Industrial Park 
Corridor and the Tlaquepaque industrial districts), simplified various governmental procedures and implemented preferential tax systems.

The temperature ranges between 13 and 32 degrees Celsius throughout the year and air is comfortably dry because it is located $1,500 \mathrm{~m}$ above sea level. Lake Chapala near Guadalajara is the largest lake in Mexico and is a well-known resort.

Because of these favorable features, many companies around the world have long recognized the excellent investment potential of Guadalajara, and began moving into the area in the 60s. Companies that began operating in Guadalajara in the 60s include Siemens (1962), Motorola (1968), and Burroughs and Unisys (1968). Later entrants included IBM in 1975, Hewlett Packard (HP) in 1982, Honda in 1985, and Kodak in 1986. In 1990, AT\&T (later the telecommunications division of AT\&T became Lucent Technologies in 1995, operated as a Lucent-Philips joint venture in 1997/1998, and then returned to Lucent Technologies in 1998 after the joint venture was dissolved) and NEC of Japan established facilities.

The North America Free Trade Agreement (NAFTA) which went into effect in 1994 assured reduced tariffs and other trade barriers to investors in the member countries, this in turn successfully attracted investment from companies based in Canada and the United States to Mexico. In 1994 and 1995, Mexico suffered from a currency and financial crisis and the value of the Mexican peso plummeted. This led to a rapid increase in foreign investment since wages became low relative to those in other countries. Contract manufacturers (CMs) such as Solectron, NatSteel, Flextronics and Jabil Circuit took advantage of the NAFTA program in 1997 (see MAP). It was around 1988 when Guadalajara began to be called the "Silicon Valley of Mexico." The name was coined in Business Week published in April 1989 (Palacios 1992). Presently, there are more than 65 electronic companies operating in Guadalajara, and the total exports by these companies amounted to approximately US\$ 6.4 billion in 1998 . This accounted for $23 \%$ of the combined sales of Mexico's entire maquiladora electronic industry (US\$27.9 billion).

\section{CASE STUDIES}

\section{OEM Companies}

As described above, the world's leading original equipment manufacturers (OEMs) such as IBM, Hewlett Packard and Motorola have built plants in Guadalajara. These companies use CMs in their innovative business management systems. OEMs use CMs to produce products that carry their original brand names, and CMs organize parts suppliers to produce electronic and information products whose life cycles are becoming increasingly shorter. The following describes the cooperative systems formed by OEMs, CMs and parts suppliers. 


\section{IBM}

As an OEM company, IBM produces desktop and laptop PCs in Guadalajara. To maximize production efficiency and minimize expenses, IBM has created new methods called internal contract production and the "Jet Way" parts purchase system.

(A) Internal contract production

IBM allows CMs to use its production lines for the manufacture of PCs. The CMs send employees to IBM's plant. Although the employees work for the CMs, they go to IBM's plant on a daily basis. One or two IBM employees, who supervise the manufacturing processes and provide technical guidance, attend each production line. By allowing CMs to operate its production lines and letting them handle various labor-related operations such as hiring, personnel management and salaries, IBM has slimed the organization and reduced costs. When IBM needs to expand production, it simply requests CMs to increase the number of employees. A cut back in production can be accomplished by requesting CMs to downsize the workforce. There are many rows of shoe shelves at the employee entrance of the IBM plant and there are more than 10 names of contract manufacturers posted on these shoe shelves. It is quite a sight when so many employees of CMs enter and leave the plant.

UREBLOCK, for example, used to supply packaging materiais to IBM in the beginning. It was gradually incorporated into the Jet Way system as a subcontract company. In addition, URIBLOCK's employees began working on IBM's production lines, and URIBLOCK has grown to be a temporary staff referral company to send workers to production lines (Dussel 1999).

(B) Jet Way

The "Jet Way" parts purchase system is basically the same as the "just-in-time" system. Parts required by IBM's production lines are ordered from suppliers located near the plant by a computer. The parts factories send the requested quantities of parts on trucks to the parts unloading sites at the IBM plant. Each site has a nameplate of suppliers (such as NABS, USI and YAMAVIR) and is installed with a belt conveyor. Delivered parts are transported to the production lines by conveyors. Depending on the production volume, one to three orders are placed each day. This parts purchase method is called the Jet Way system (see Figure 2) since the parts unloading facilities, the way parts are fed to the production lines, and the product shipping process resemble the operations and facilities of airports such as airplane parking areas, passenger loading areas and boarding walkways.

IBM pays only for the parts used in completed and shipped products, thus eliminating the need to stock parts (zero inventory) and thus transferring the risk caused by fluctuating product demand to the suppliers. Since IBM pays only for parts used in the products sold, it can achieve substantial cost reduction. Most of the suppliers have a long association with IBM. Suppliers generally supply parts to companies other than IBM since depending only on IBM's orders can cause parts sales to fluctuate with the sales of IBM products. 


\section{Hewlett Packard}

Hewlett Packard (HP), a well-known OIM company, manufactures low-price PCs, laser jet printers and servers. This company also makes full use of CMs. HP does not have a production line. The company uses CMs to produce basic HP product models (external contract production system). HP receives basic product models from CMs and makes specification modifications and final adjustments according to product destinations. These operations include the setting of power supply voltage (100 VAC, $220 \mathrm{VAC}$, etc.) and frequency $(50 \mathrm{~Hz}, 60 \mathrm{~Hz}$, etc.) and packing of manuals in the language of the product destination (English, Spanish, etc.). Then, HP packages and ships products. HP calls the processes and procedures conducted at the HP site "integration" (see Figure 4). HP in Guadalajara is in a sense a huge warehouse without a factory function.

The number of employees working at the HP site is 1,142 (400 full-time workers and 742 workers in contracted factories). People engaged in the manufacture of HP products in externally contracted production total 6,160 (4,930 at CMs and 1,230 at suppliers). HP has created jobs for 7,302 people in total.

HP in Guadalajara originally operated as a production plant of mini-computers for the US market, and gradually expanded production for the world market. It then changed the facility to a distribution center for the Latin American market. In line with its globalizing operations, HP in Guadalajara began serving as the Latin American regional integration business center for Europe and Asia. It is also a design center for laser jet printers for the world market. The printers produced in HP plants in the United States, Germany and Japan are designed here.

\section{Features of OEM companies}

OEMs have their products manufactured by CMs, and they focus efforts on $\mathrm{R} \& \mathrm{D}$, product concept planning, design, development of manufacturing process technologies, distribution, marketing and advertising. IBM uses the internal contract production system, while HP relies on the external contract production system. Both companies draw on their established brand names, and contract other companies for product production so that they can minimize manufacturing costs, personnel expenses and inventories. They strive to increase profits by reducing costs and shortening the lead time and allocate limited management and personnel resources to research and development as well as production distribution and services to enhance customer satisfaction. They also utilize information technology (IT) to make quick decisions.

The life cycles of electronic products are now extremely short. Due to rapid advancement of technology, parts are quickly replaced with newly development counterparts. This is the reason why electronic parts are sometimes called "lettuce". Under such condition, it is detrimental for a company to keep large quantities of parts in stock. Inventory control is now highly important, and OEMs avoid keeping parts in stock and aim to achieve zero inventory.

In recent years, many American companies have been closing their factories in 
the United States and transferring their production facilities to Mexico. IBM plans to close its disc drive device factory in San Jose, California and open a plant in Guadalajara. To boost the competitiveness in the market, IBM is strategically concentrating production functions in areas where investment is more effectively put to use because of the exchange rate and lower wages.

\section{Contract manufacturers (CMs)}

CMs produce products for OEMs on contract. Five of the world's top six CMs have plants in Guadalajara. These companies are SCI Systems, Solectron, Jabil Circuit, Flextronics and NatSteel [world's top three companies by sales in 1997: SCI Systems (US\$ 6.4 billion), Solectron (US\$ 4.0 billion) and Celestica (US\$ 2.0 billion)]. We visited all five companies, and observed various reforms made in their parts supply systems. These five companies are involved mainly in the production of printed circuit boards (PCBs) and assembly of PCBs and complete PCs and other products.

Each CM manufactures products for several companies such as OEMs and computer manufacturers, and in the CM's plant each production line is posted with the name of the company (examples: HP line, DELL line, Ericson line etc.) to which the manufactured products are delivered. The sight of 10 production lines simultaneously manufacturing products of different companies is quite impressive.

To improve production efficiency, CMs do not devote their entire facilities to the manufacture of products of a single company. Furthermore, in order to maximize the scale merit, CMs tend to make sizable investment in facilities, especially in recent years. CMs have achieved effective small-lot multi-product production systems. To streamline parts supply, CMs basically employ the "just-in-time" system. Parts for PCs are usually imported from Asia and the United States, but many innovative ideas have been incorporated in the parts supply systems in recent years, such as (1) campus concept and (2) hub concept.

According to the campus concept, a CM company provides (sells) factory sites to supplier companies for the construction of their plants for its parts production. The concept was so named because the plant layout looks like a university campus where different departments such as engineering and economics are located at a given site. This system provides various advantages to CMs, such as reduced transportation costs, shorter delivery time, improved quality and easier information exchange, since suppliers' factories are located within the proximity of the CM's plant. This system provides greater benefits when procured parts have small added value and are bulky and used in large quantities (molded plastic parts, stamped parts etc.). The campus concept results in "holding" of parts companies by CMs. American CMs bring their American parts manufacturing companies when they establish plants in Guadalajara. It is similar to Japanese companies taking their parts manufacturing subsidiaries with them when they establish overseas plants.

The hub concept calls for a more flexible and larger system (see figure 3). This concept requires the establishment of a parts pooling facility. Parts suppliers de- 
liver their products to this facility and CMs procure products from there. Just as many airline companies use a hub airport, a hub facility is utilized by a number of suppliers and CMs. A hub facility is operated and managed by an independent company. Suppliers, hub facility managing company and CMs use a computer network (EDI or Electronic Data Interchange) for inventory control, order placing and order receiving. Establishment of parts supply hub facilities began in Guadalajara in 1998.

Incidentally, CMs are very energetic in quality control activities and inspections and actively obtain 1SO9000, 1SO9002 and other quality standard certifications.

\section{Jabil Circuit (JBL)}

JBL was established in 1966 in Michigan and moved its head office to Florida in the 80s. Today, the company has plants in Florida, Michigan, California and Idaho as well as in Scotland, Italy, Malaysia and Mexico. JBL's Mexican plants are located in Guadalajara and Tijuana. The number of employees working for JBL worldwide totals more than 6,000. The company's annual sales reached US\$ 1.1 billion in 1997, making it the fourth largest CM in the world. The company produces data network products $(35 \%)$, PCs $(20 \%)$, communications equipment $(15 \%)$, peripheral devices $(15 \%)$, automotive electronic parts $(10 \%)$ and others (5\%). Its clientele includes HP, Apple Computer, DELL, Cisco Systems, 3 COM, Whirlpool and GM.

JBL's Guadalajara plant began operation in 1997. It is located on a 25 -acre site and is equipped with 14 manufacturing lines. The plant has 1,335 employees (953 directly hired workers, 188 indirectly hired workers, 52 technicians and 60 engineers). It operates seven days a week with 17 shifts ( 3 shifts on Monday through Friday and 2 shifts on Saturday) for the manufacture of mother boards, laptop PCs, tape drive controllers, and network products. The majority of products are exported to its customers in the United States, such as Celnet, Whirlpool, Cisco, Quantum, 3 COM, DELL and Gateway.

JBL purchases most of the parts from suppliers in the United States, but it also procures parts from American companies located in Mexico using an on-site supplier management system. Products purchased from Mexican companies account for about $2 \%$, and they include raw materials of plastics, metal materials (laminated sheets and others) and packaging materials. JBL uses a computer inventory management system such as an MRP (material requirement planning) program.

\section{SCI Systems}

SCI Systems has its head office in the United States. With annual sales of US\$ 6.4 billion in 1997, the company is the largest CM in the world. SCI Systems began operation in Mexico in 1987 when its 16th plant was constructed in Guadalajara. Since then, the company established its 24th plant in Mexico City, 28th plant in Monterrey and 29th plant near the Guadalajara airport. SCI Systems has a total of 
59 manufacturing lines in Mexico with more than 6,900 employees working in these plants. The company's annual sales in Mexico were US\$1.3 billion in 1998 .

We visited SCI Systems' 16th plant. The facility has 37 lines and uses 2,975 workers (1,904 directly hired employees and 1,071 indirectly hired employees). Also working at this plant are 165 technicians and 670 engineers, 18 of whom have doctorate degrees. Products manufactured in this plant include motherboards, printer circuit assemblies, desktop jet printers, modems, satellite receivers, headphones and bar-code readers. The president of this plant is a Mexican woman by the name of Yolanda Flores.

This plant uses a hub system for parts procurement. The company purchases parts from the hub run by CDI (International Distribution Center; a joint venture of American and Mexican companies) through computer networks. Manufactured products are transported to the SCI logistics center in San Antonio in the United States before being distributed nationwide.

\section{Flextronics}

This company was originally set up in Singapore in 1982 and Flextronics International was established in 1995 in San Jose, California. Flextronics' sales in 1997 were US\$ 950 million, and the company ranks fifth. Its Guadalajara plant began operation in 1997. The plant site measures 38 acres, and 1,000 people are employed. It manufactures PCB assemblies, modems, motherboards, circuit breakers, flash memory devices, bell boards and others. The president, Brad Knight, is an American born in San Jose.

This plant draws on the campus concept and uses a group of American parts companies which purchased lots and constructed factories on the site (Flextronics Industrial Park in Zapopan). Presently, plastic molding company (DTM) and stamping company (BERMO) are operating there. Three more companies are scheduled to begin operation on the plant site. Establishment of factories that produce bulky parts consumed in large quantities on the same plant site is advantageous to Flextronics.

\section{NatSteel Electronics}

NatSteel was established in Singapore in the early 1960s. The company has since grown, and the head office has moved to San Jose, California. With annual sales of US\$ 800 million in 1997, it is the sixth largest CM in the world. NatSteel's Guadalajara plant started operation in 1997. Some 1,600 people work at the plant to produce $\mathrm{PCB}, \mathrm{PCB}$ assemblies and photo-smart printers. The president is a Singaporean by the name of Loh Hung Chee. Manufactured products are supplied to HP, IBM, Xerox, Panasonic and others.

NatSteel imports about $90 \%$ of parts from Asia and the United States. There is a plan for the construction of a hub parts supply facility. According to the plan, the hub facility will be managed by a Singaporean company (YCH). 


\section{Suppliers}

In Mexico, there is a shortage of suppliers, and domestic production of key parts cannot meet the demand. To solve this problem, the Mexican government is striving to establish a system that supplies parts manufactured in Mexico and foster small and medium-scale enterprises (SMEs) or what we call "supporting industries". Along with these efforts, OEMs and CMs in Guadalajara have jointly formed an organization called CADELEC (Suppliers Development for the Jalisco Electronics Industry) to collect information of parts and parts companies with the aim of establishing an original parts supply system. CADELEC serves as a bridge to connect OEMs, CMs and suppliers.

CUMEX is the only Mexican company capable of producing PCBs (CADELEC 1999). This company is located in the city of Guadalajara. The company was established with 50\% capital from the US and 50\% from Mexico. It can produce one sided, double-sided and 4-layer PCBs. The fact that there is only one Mexican PCB manufacturing company indicates the insufficiency of parts supplies in Mexico.

\section{CADELEC}

CADELEC is a match-making organization to introduce parts suppliers to CMs and OEMs in Jalisco. This industry association, initiated by Lucent Technologies and formed with the cooperation of IBM, HP, INTEL and NatSteel, aims to construct a system that can ensure supply of high-quality parts to respond to the needs of OEMs and CMs in Guadalajara. CADELEC began operation in february 1998. CADELEC was established with $1 / 3$ of the funds from the above companies, $1 / 3$ from the Jalisco state government, and 1/3 from the industrial integration program (program based on the federal government's fund for Small and Medium-scale Enterprises, the Mexican Chamber of Industry Council and the United Nations Development Program). The chairperson of CADELEC is presently E. Valtierra, the former president of Guadalajara INTEL. The organization provides information on parts demands of OEMs and CMs, makes lists of suppliers, conducts PR activities, offers information services, and produces data-base and research reports. According to CADELEC's first report, PCBs Industry 1999, demand for PCBs in Jalisco in 1999 was estimated to be 11 million square feet or US\$188.62 million.

Each member pays an annual fee of US\$1,000 to CADELEC, and has access to the information on the Internet. The number of members is presently about 20 .

There are other similar organizations in Mexico that introduce companies and aim to foster parts manufacturing companies, such as CEDEP (Suppliers Development Center) in Chihuahua, CEDEP in Guanajuato and EDC (Economic Development Council) in Tijuana (Michael Piore and Clemente Ruiz Durán 1998).

\section{YAMAVER}

YAMAVER was established in 1996, and completed the construction of a factory in 1997. It is a joint venture company founded by Yamashita Electric Co. 
(Japan), Verco (Belgium) and Manesa (Mexico), each paying in an equal amount of capital. Combining these three companies' names made the company name. Yamashita Electric invested in the project since it had been supplying parts to IBM Japan for many years.

With 240 employees, YAMAVER supplies plastic covers and liquid crystal displays (LCDs) panel subassemblies for notebook PCs to IBM's Guadalajara plant (YAMAVER has recently begun providing parts to HP, too). YAMAVER is incorporated in IBM's Jet Way system so IBM does not keep its parts in stock.

The company imports LCD panels from Korea (LG). It orders almost all necessary parts from Japan and other Asian countries. It purchases only plastics in Mexico. YAMAVER is now providing technical guidance to a Mexican company so it can produce electroless plated parts for wave interference prevention.

IBM's laptop PCs (ThinkPad) were developed and designed in Japan. About $60 \%$ of the 2 million IBM laptop PCs produced annually are manufactured in Guadalajara.

\section{NEW INDUSTRIAL NETWORKS}

\section{Change of management policies and reorganization of corporate networks}

Guadalajara is home to companies that provide OEM brand names, such as IBM and HP. There are many CMs (Solectron, SCI, Jabil Circuit, etc.) in Guadalajara that manufacture products for OEMs on contract. Virtually all these companies operate based on management policies that place high priorities on maximum customer satisfaction (CS), and they manage their supply chains accordingly. Optimization of a supply chain network requires the improvement of the entire value chain consisting of a series of processes and stages such as (1) R\&D, (2) design, (3) parts procurement, (4) personnel development, (5) production, (6) product marketing and (7) after-sales service. In other words, the focus has shifted from cost minimization to customer satisfaction enhancement. Companies are redesigning their supply chains in order to respond to customers' needs.

To provide customers with higher satisfaction, companies must find out what customers want, then supply products at lower prices (cost cutting efforts), improve quality and offer prompt services. To create added value, companies make their products different from others or add distinctive features and functions. For example, Jabil Circuit places emphasis on design, and the company has increased its number of designers. SCI, on the other hand, is focused on testing. When priorities are placed on the three factors described above (low prices, high quality and prompt services), corporate activities become different from those aimed at reducing manufacturing costs.

Faced with such a dramatic change in management policies, companies must express originality in their products to achieve business growth. Before optimizing a supply chain network, it is necessary to identify which section of the supply chain 
to add originality to, which customer group (large corporations, medium-scale companies, governmental organizations, educational institutions, small businesses, general consumers etc.) to provide enhanced satisfaction to, and which demand to meet. The "just-in-time" system is a method to improve production efficiency by reducing parts inventories in production processes, and it should be considered as a part of the supply chain. While most Japanese companies have focused on manufacturing technologies, including the "just-in-time" system, American companies have been reforming management systems by examining the entire supply chain. Larger cost reduction is possible when the entire supply chain is streamlined than when efforts are made only in the production line. To achieve higher customer satisfaction, it is more effective to optimize the supply chain than improving the production line. In this regard, a distinctive supply chain network system was observed in Guadalajara. For the sake of convenience, let's divide a network into three stages: (1) OEMs, (2) CMs and (3) suppliers. In each of the groups, the key points stressed by companies are different. HP, an OEM company, emphasizes the importance of R\&D within the supply chain, product development and design, and logistics strategies for product distribution and sales. Brand image is the key for these operations. Products developed and designed by HP are consigned (outsourcing) to CMs. This reduces HP's risk and results in lower costs for HP. OEMs that operate this way are "service" companies rather than manufacturing companies. Since these companies use their brand names (such as IBM and HP) to sell products, their business function becomes dose to that of the apparel industry. They market their products in the same way as Gucci and Chanel sell products of original design carrying their brand names. Therefore, product design and marketing become highly important for OEMs to achieve success in business.

$\mathrm{CMs}$, on the other hand, handle the manufacturing function. CMs are charged with the responsibility of providing products that satisfy the required quality, price and delivery schedule in accordance with the orders placed by OEMs. To lower product prices, CMs must implement cost-cutting measures while maintaining quality. Profit rates are becoming lower for CMs due to the standardization of products that has been promoted in recent years. An average profit rate is said to be less than $5 \%$. The same products (such as PCBs) are sold to different companies with only minor specification changes. For CMs to increase profits, they must sell large quantities of products. In the electronic industry, facility investment is large and the labor force must be concentrated in certain production processes. CMs invest large amounts of money in facilities and hire workers at low wages to increase the profit margins. The demand for CMs is growing, and companies such as Solectron and SCI have seen rapid growth. Therefore, more investment is expected to be made in the future.

CMs need suppliers that manufacture and provide parts. In Guadalajara, there are not enough suppliers capable of meeting the needs. Many CMs rely on imports from Asia. There are two ways to solve the problem: by transferring production bases from Asia to Mexico or by fostering local suppliers. Although the foundation necessary for fostering local suppliers exits in Mexico, it is not adequate or suffi- 
cient; therefore, it is necessary to attract Asian companies to establish production facilities in Guadalajara for the time being.

\section{Different supply chain networks formed by various companies}

Multinational companies are striving to optimize their supply chain networks on a global scale. Is global optimization of supply chain networks possible? To do so, companies must place the highest priorities on customer satisfaction in their management policies and execute regional integration strategies. In other words, companies need to implement region-specific strategies for Asia, Europe and America. Asian strategies are for the entire East Asian region except for China. Production bases of European manufacturing industries are usually located in East Europe (Poland, Hungary etc.). American companies' manufacturing bases are often located in Mexico. While Brazil and Argentina form a South American economic bloc, Mercosur. Multinational corporations from around the world are operating in Guadalajara. From Japan, NIC and Honda have established production bases in Guadalajara. Each company is using its original production system. The key to establishing a production system that is different from others rests on how outsourcing strategies are used to reduce costs and risks and to flexibly respond to market needs for higher customer satisfaction. The following section describes with diagrams the differences in the outsourcing strategies of (I) Lucent Technologies, (II) IBM, (III) NatSteel and (IV) HP in Guadalajara. Lucent Technologies operates on a basic policy of in-house production. Lucent Technologies ${ }^{1}$ produces AT\&T's telephones under a licensing contract as well as cellular phones and other communications equipment. It produces parts in-house as much as possible in order to accumulate technologies.

In the following example, we reduced the number of production processes (OPs) to three for simplification. As shown in Figure 1, Lucent Technologies has necessary in-house parts manufacturing factories (suppliers $\mathrm{S}$ ) for three production processes OP1, OP2 and OP3. With this production system, the company can accumulate production technologies, but it must bear the cost of inventory. It lacks flexibility to allow the use of different parts to enhance customer satisfaction.

One way to switch to an external parts purchase system to compensate for the drawbacks of traditional in-house production system is to use the campus concept. Flextronics uses the campus system; the company had parts companies build factories on Flextronics' plant site. IBM took a different approach with the Jet Way system (see Figure 2); IBM contracts out the production of necessary parts. In both systems, a multiple number of CMs are used to promote competition. They replace

\footnotetext{
${ }^{1}$ AT\&T's telecommunications division spinned out to be Lucent Technologies in 1996. After a short and unhappy marriage with Philips Electronics, it came back to the original name in 1998. Since then, Lucent in Guadalajara had been on sale and finally VTech, a Hongkong-based company, bought it in February 2000.
} 
incompetent companies with manufacturers with higher capability. They also change CMs in accordance with customers' needs to provide maximum satisfaction. In addition, IBM pays for parts when completed products are shipped, so IBM can minimize the interest on inventories. YAMAVER, one of the suppliers for IBM, sometimes receives one or more orders on a daily basis. Although IBM believes in the principle of competition, it prefers mid- and long-term relationships with CMs and suppliers. IBM takes medium- and long-term relationships into consideration rather than opting for full-scale outsourcing.

NatSteel plans to use the hub system (see Figure 3) in Guadalajara. With this system, the company shifts the financial burden of parts inventory to other companies and also outsources parts procurement management operations. The hub system requires a separate company for parts procurement operation and management. The management company does not manufacture parts but has a warehouse to store parts purchased from a number of companies. NatSteel's parts procurement company will use the Internet and information technology (IT) to supply parts to NatSteel according to delivery schedules (" just-in-time”). ${ }^{2}$

Outsourcing is maximized in HP's integration system (see Figure 4). HP does not manufacture parts. It uses CMs for the production of finished products, and modifies (integrates) the basic products delivered from CMs to the final specifications and packages them. Modifications include the setting of power supply specification and packing of manuals written in the language of the destination market.

How does HP develop originality through the integration system? To maintain and enhance the brand reputation, it is necessary to spend efforts on research, development and design as well as on implementing logistics strategies including PR to strengthen the brand image. This also applies to IBM. HP has no production processes (OPs), and its operations involve only the integration of products manufactured by CMs. In other words, HP is not a manufacturing company; it performs operations similar to those of the service industry. Since the company must create originality through product development and design, its function becomes dose to that of the apparel industry.

\section{COST-RELATED PROBLEMS: DISCONTINUATION OF MAQUILADORA PROGRAM}

As mentioned previously, companies operating in Guadalajara import more than $90 \%$ of electronic parts used in their products. Asia is the primary supplier of those parts. As OEMs and CMs are facing intense competition today, the profit rates are low. Therefore, cost affecting factors such as tariffs are the key element that determines the business performance of companies. According to the president

\footnotetext{
${ }^{2}$ Solectron Corporation, the world's leading provider of electronics manufacturing and supply-chain CM, acquired NatSteel Electronics in January 2001.
} 
of Flextronics, Mr. Knight, the profit rate is about 3\% and tariffs set any higher will reduce profits to zero and cause CMs to leave Guadalajara.

The biggest problem facing foreign-capital electronic companies in Mexico is the abolishment of the maquiladora program in 2001. Maquiladora companies are exempt from customs duties on parts imported and used in products to be exported. A similar program called PITEX (program for temporal importation of goods to produce articles for export) is available to non-maquiladora companies. When these programs are discontinued, companies must pay tariffs on parts imported from countries that are not NAFTA members. Most companies we visited were either maquiladora companies or PITEX approved.

For example, before November 1998 the tariff was $18 \%$ on multi-layer PCBs from Asia and 13\% on one-side PCBs. The electric and electronic industry negotiated with the federal government regarding the discontinuation of the maquiladora and PITEX programs. Consequently, in November 1998 the category tariffs for PCBs were reduced uniformly to $5 \%$ for the reason of promoting the industry's further growth (electronic parts are classified in either $0 \%$ or $5 \%$ tariff category).

From 2001, Mexican tariffs and US tariffs will have the following effects on parts from Asia. Suppose a company imports a PCB from Asia, for which the Mexican duty is US\$ 5, and the final product made with that PCB is exported to the US, for which the US customs duty is US\$ 6. According to the new NAFTA provisions, the company is waived from paying the smallest tariff - in this example, the US\$ 5 Mexican duty. Therefore, the tariff that must be paid to Mexico for the import of the partis zero (US\$ 5 - US\$ 5 = US\$ 0 ) (see example 1 in Table 1).

Since Mexico's customs duties on parts imported from Asia are higher in comparison to American duties, the new system can affect foreign investment in 2001 and subsequent years, and the Mexican government hinted at the possibility of reducing tariffs in some product categories.

Table 1

New Tax Provisions for Maquiladora and PITEX Programs

Scheduled for Implementation in 2001 (Unit: US\$)

\begin{tabular}{|c|c|c|c|c|}
\hline \multicolumn{2}{|c|}{ (1) } & $(2)$ & (3) & (4) \\
\hline & $\begin{array}{c}\text { Mexican duty } \\
\text { on goods (A) } \\
\text { from Asia }\end{array}$ & $\begin{array}{l}\text { USA duty on } \\
\text { final products made } \\
\text { with goods }(A)\end{array}$ & $\begin{array}{l}\text { Duty waived by } \\
\text { NAFTA [smallest } \\
\text { of (1) and (2) }\end{array}$ & $\begin{array}{l}\text { Net Mexican duty } \\
\text { charged on goods } \\
\text { (A) from Asia }\end{array}$ \\
\hline Example 1 & 5 & 6 & 5 & 0 \\
\hline Example 2 & 5 & 0 & 0 & 5 \\
\hline Example 3 & 11 & 2 & 2 & 9 \\
\hline
\end{tabular}

Source: CADELEC.

\section{CONCLUDING REMARKS}

An electronic industrial cluster has been formed in Guadalajara; a city located $570 \mathrm{~km}$ northwest of Mexico City. This industrial community is made up of three 
layers. The first layer is composed of OEMs such as IBM and HP. The second layer consists of contract manufacturers (CMs) such as SCI, Flextronics and NatSteel. Suppliers which provide parts for OEMs and CMs form the third layer.

OEMs in Guadalajara, such as IBM, are undergoing drastic mutation. As OEMs have already established brand names, they rely on outsourcing for production. The primary aim of OEMs is to establish a supply chain network that provides the highest level of customer satisfaction. These companies are focused on creating management and system procedures that achieve this objective. As a consequence, the function of OEMs is now becoming closer to that of the service industry than that of the manufacturing industry.

The key strategy for network establishment is global optimization. Companies are optimizing their supply chain networks in each of three regions: Asia, Europe and North and South America (the Americas). Mexico has become the production base for the North American market mainly because of the NAFTA program.

There are three points to which we must pay special attention. First, many companies do not include China, India and Brazil in their global network optimization plans. The main reason for this is that these countries have large markets and have their own industrial policies that have been causing a delay in deregulation.

For these markets, companies must plan and implement country-specific strategies. Secondly, the discontinuation of the maquiladora program in 2001 has highlight the competitive nature of the relationship between Asia and Mexico - large quantities of parts are imported to Mexico from Asia - because of the 5\% tariff on those parts, foreign-capital companies in Mexico are considering shifting their production bases from Mexico to Asia. The profit margin is small (less than 5\%) and severe competition is forcing companies to further reduce costs. Under such circumstances, it is inevitable that Asian countries and Mexico will compete with each other to attract foreign companies.

The third point is the need to create more suppliers. This is a common problem in developing economies. Mexico has to develop supporting industries and foster personnel. Activities led by the private sector such as CADELEC (cooperative organization of OEMs, CMs and suppliers) suggest this urgent need.

As explained in this paper, globalization is rapidly taking place in OEMs and CMs. Multinational corporations are establishing and implementing regional strategies in the three regions - Europe, Asia, and the Americas - and also global strategies. Multinational OEMs have long since implemented separate strategies in these three regions to respond to individual market characteristics with the aim of achieving maximum customer satisfaction in each market. To this end, they decided to use external companies to produce their products (outsourcing) and concentrate company efforts on design, $\mathrm{R} \& \mathrm{D}$, distribution and marketing operations. In other words, they have changed from manufacturing companies to "service" companies. Meanwhile, CMs have established manufacturing facilities near OEMs to handle their production needs on contract, and organized their parts supplier networks. Although the markets in Europe, Asia and the Americas seem independent of one another, companies use global networks for the design development and parts 
procurement to supplement operations in those regions. Thanks to advanced information technology, particularly the Internet, information can be communicated instantaneously and processed immediately. Speed, resolute decisions and dramatic reforms have supported the prosperity that the electronic industry is enjoying today.

Japanese companies, on the other hand, are implementing relatively detailed and localized strategies in Asia, but do not have regional strategies for Europe and the Americas or global strategies. As indicated by the extremely small investment of Japanese companies in Mexico as compared to American and European counterparts, Japanese industries are behind others as far as corporte activities in Mexico are concerned. Japanese manufacturers tend to place stress on production technologies and manufacturing quality. The "just-in-time" method and "cell-production" system are basically cost cutting and efficiency improving techniques for manufacturing processes, but they do not achieve cost reduction or efficiency enhancement seen through the change of the entire corporate management system. In other words, Japanese firms have to change from ideas based on the traditional pyramidshaped subcontracting system (or paternalistic culture) to a way of thinking based on independent purchasesale relations (or selective culture). Japanese manufacturers have not yet converted themselves to "service" companies taking the whole value chain into consideration. European and American companies have taken the lead in software development, and Japanese companies concentrated too much effort on the production of hardware, especially DRAMs. The Japanese industry did not make a proper judgment regarding advanced information networking technology and remained behind as far as the production of communication-related high-performance semiconductors and equipment is concerned. In addition, Japanese companies still believe that high product quality cannot be maintained unless parts are made in-house. The decision-making speed of corporate management is also slow. Japanese people cannot communicate smoothly in English which is the universal language used on the expanding Internet. In view of this, it is interesting that Flextronics, a Singaporean CM, is successfully conducting business in Guadalajara.

Breakthroughs in the electronic industry are taking place quietly in the "Silicon Valley" in Guadalajara. There are a lot of lessons to learn from the "South."

\section{REFERENCES}

CADELEC, PCBs Industry 1999, Guadalajara, 1999.

DUSSEL, Enrique, La subcontratación como proceso de aprendizaje: el caso de la electrónica en Jalisco (México) en la década de los noventa, CEPAL, Santiago, 1999.

\footnotetext{
${ }^{3}$ Due to an IT recession in the US, Guadalajara region has been affected by severe demand contractions. From the fourth quarter of 2000 to the first quarter of 2001 several factories in this region, such as NEC, NatSteel (Solectron), and VTech were actually forced to shut down.
} 
PALACIOS, Juan José, “Guadalajara: valle del silício mexicano”, Tiempos de Ciencia, n 27, abril-junio 1992.

PIORE, Michael and RUIZ DURÁN. Clemente, "Industrial Development as a Learning Process: Mexican Manufacturing and the Opening to Trade", in M. Kagami, J. Humphrey, and M. Piore (eds.) Learning, Liberalization and Economic Adjustment, Institute of Developing Economies, Tokyo, 1998.

\section{Figure 1}

Internal Production System of Lucent Technologies (OEM company)
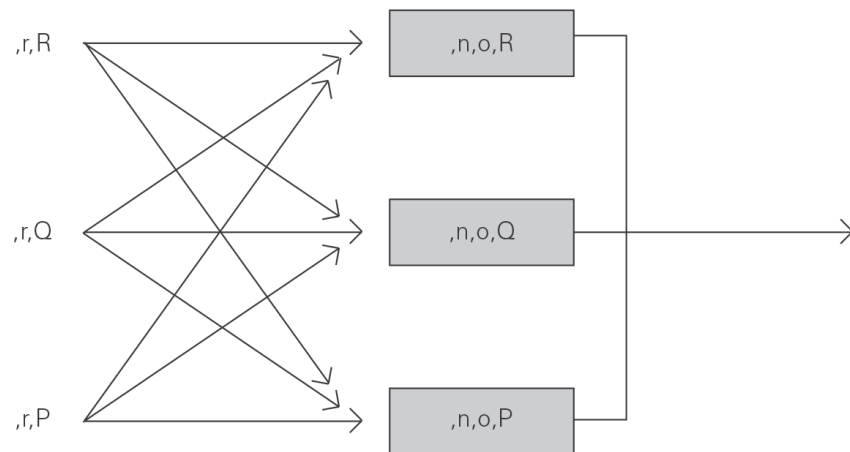

Customer

$$
\ulcorner-----\rightarrow \quad \text { Corporate Boundary }
$$

(Note)

OP1: Production process 1

S1: Parts supplier

Source: Produced by the author.

Figure 2

Jet Way System of IBM (OEM company)

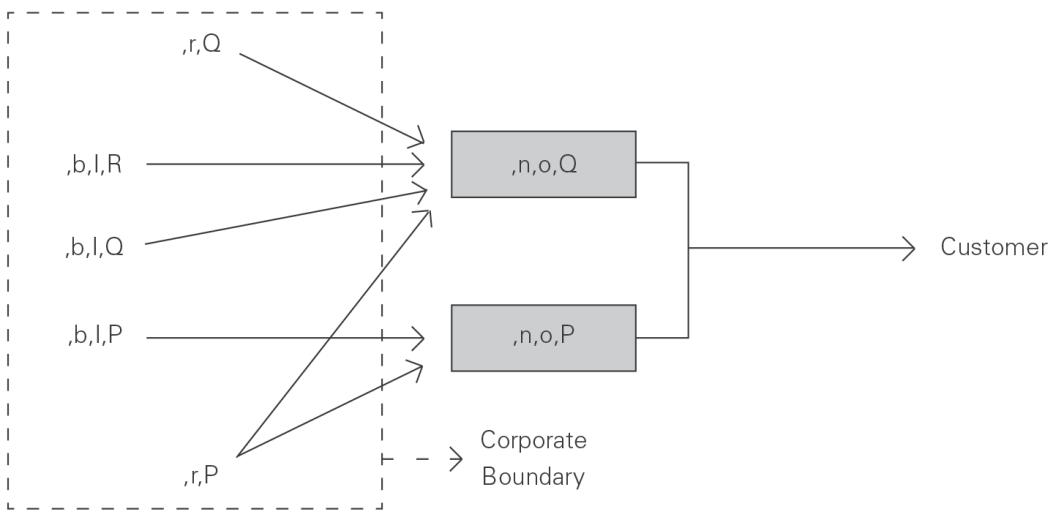

(Note)

S1: Supplier 1

CM1: Contract manufacturer 1

$\mathrm{CM} 2$ and CM3: Competing production in OP2 (production process 2)

Source: Produced by the author. 
Figure 3

Hub System of NatSteel (Contract Manufacturer)

$, \mathrm{r}, \mathrm{R}$

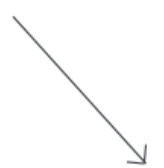

$, \mathrm{r}, \mathrm{Q}$

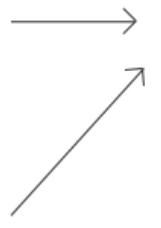

$, \mathrm{r}, \mathrm{P}$

(Note)

S1: Supplier 1

OP1: Production process 1

Source: Produced by the author.
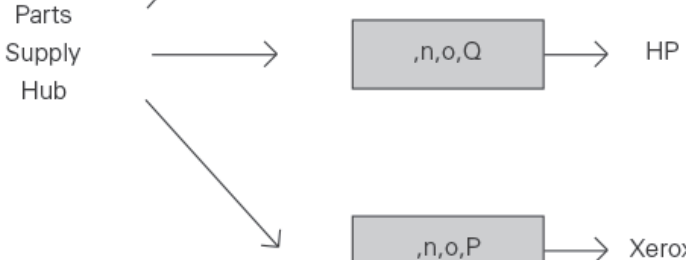

$--\rightarrow \begin{aligned} & \text { Corporate } \\ & \text { Boundary }\end{aligned}$

Figure 4

Integration System of Hewlett Packard (OEM company)

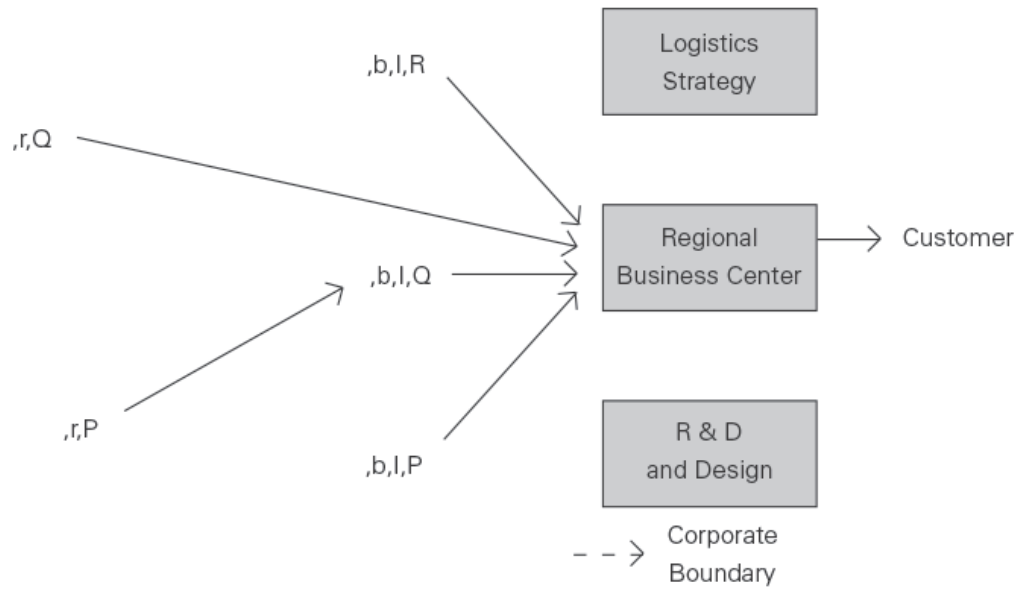

(Note)

$\mathrm{CM} 1$ : Contract manufacturer 1

S1: Supplier 1

Source: Produced by the author. 